\title{
Sobre a Ontologia Menfita: uma investigação afrocêntrica
}

\author{
On Menphite Ontology: An Afrocentric Inquiry
}

VALTER DUARTE (D)

\section{Resumo}

É de conhecimento geral a opinião comum segundo a qual a cosmogonia egípcia antiga descreve a criação do mundo como partindo de uma realidade caótica sequenciada pelo estabelecimento de uma ordem criadora. O presente trabalho representa a investigação inicial de uma pesquisa em andamento acerca da precisão de tal rota interpretativa. Esse esforço será realizado a partir do método afrocêntrico, sistematizado pelo Dr. Molefi K. Asante.

Palavras-chave: Afrocentricidade. Filosofia. Filosofia Clássica Africana. Ontologia. Kemet.

\section{Abstract}

It's common knowledge the opinion which presents the ancient Egyptian cosmogony as describing the creation as rising from a chaotic reality sequenced by the establishment of a creative order. This paper represents an initial inquiry of an ongoing research on the accuracy of such an interpretative route. This effort will be carried out using the Afrocentric method, systematized by Dr. Molefi K. Asante (1987; 1990; 2014).

Keywords: Afrocentricity. Philosophy. African Classical Philosophy. Ontology. Kemet.

\footnotetext{
a Universidade do Estado do Rio de Janeiro (UERJ), Rio de Janeiro, RJ, Brasil. Doutor em Filosofia, e-mail: valtermoreira2@gmail.com
} 


\section{Introdução}

Quando tratamos do assim chamado Egito antigo (doravante referido como Kemet) no ambiente acadêmico enquanto tradição filosófica, somos surpreendidos com reações bastante comuns de surpresa e espanto, já que se trata de um tema não frequentado. Embora seja este um tema curiosamente incomum no solo acadêmico da filosofia no Brasil, o assunto é de certa maneira bastante conhecido entre os corredores ao longo do país, no interior dos quais circulam concepções dogmáticas acerca desses povos. O presente trabalho foi realizado com o objetivo de iniciar um processo de investigação acerca das investigações de caráter ontológico dos povos egípcios antigos (doravante referidos como keméticos), investigando se a concepção comum acerca desse tema é o caso para esses povos.

Para realizar esse trabalho, utilizaremos as informações contidas nos textos primários conhecido ora como Papiro de Ani (FAULKNER; GOELET; GUNTHER, 2015), ora como O Livro do Vir-a-Ser à Luz do Dia (ASANTE, 1990), hoje acervo do Museu Britânico. A escolha do texto se dá pelo fato conhecido entre especialistas de que o conteúdo da obra remete a questões fundamentais levantadas por aqueles povos desde seus períodos mais remotos (cf. KARENGA, 2004), o que nos dá acesso ao corpo conceitual utilizado pelos filósofos e filósofas da cultura kemética.

Nossa investigação permitiu elucidar algumas questões, levantar outras e retirar parte do véu de mistério e obscurantismo que envolve as questões filosóficas referentes ao povo kemético e suas produções. Além de servir como material didático para o cumprimento da Lei no 10.639/03, promulgada em 2003.

\section{O conceito de Nwn}

A leitora e o leitor irão perceber que embora nossa investigação tenha como alvo questões de ontologia, esse artigo apresenta informações de caráter ético. Tratase de um traço comum da tradição filosófica africana (ASANTE, 1990, 2016; DIOP, 2014), sobre o qual trataremos em outro trabalho. Em linhas bastante gerais, é considerável o número de pessoas no Brasil que sabe ser a ontologia, de maneira geral, o ramo da filosofia que lida com questões relacionadas à existência. Qualquer uma 
delas que se interesse e busque mais informações sobre o assunto perceberá, nas várias bibliotecas à nossa disposição, que a tradição ocidental legou à humanidade caras e profundas reflexões. Se for uma pessoa desatenta ao tomar como base o acervo dessas bibliotecas, em algum momento de seu próprio raciocínio tomará como verdadeira a falsa implicação de que a tradição ocidental reúne, nela mesma, as respostas mais sofisticadas para os desafios da humanidade. Como certamente esse não é o caso das pessoas que chegaram a esse artigo seduzidas pelo título e pelos caminhos que o resumo indica serem trilhados, nos basta justificar que esse artigo dá seguimento a uma série de questões e segue o andamento de uma pesquisa acerca do conteúdo das reflexões filosóficas inscritas nos papiros da cultura clássica africana.

A busca superficial nessas bibliotecas nos mostra um amplo véu místico e misterioso, além das várias generalizações ingênuas que compõem esse fenômeno de encobrimento como acessórios do mistério. Quando o assunto é ontologia, essas generalizações produzem afirmações do tipo "para os povos egípcios, antes da existência ordenada havia o caos". Ao nos questionarmos sobre esse tema, buscamos acessar os textos primários dos antigos egípcios (doravante referidos como keméticos).

Em suas dimensões ontológicas ${ }^{1}$, encontramos a cosmogonia kemética apresentando diferentes versões. Contudo, essas versões carregam um padrão comum: Elas estão divididas em pelo menos 4 etapas: as duas primeiras dizem respeito ao caráter do real que autores como o Dr. Mubabinge Bilolo (2008) e o Dr. Molongwa Bayibayi (2017) chamam de meta-ontológico ${ }^{2}$ (BILOLO, 2008) e autores como o Dr. Molefi Asante (1990) e o Dr. Maulana Karenga (2004) chamam de pré-criação (uma

\footnotetext{
${ }^{1}$ Por estarmos nos comunicando através de um idioma ocidental, esse termo (bem como outros mencionados ao longo do trabalho) é utilizado pelo bem do entendimento da leitora e do leitor. O que significa que tomamos seus sentidos de forma ampla e com referência não específica a um, ou outro trabalho dos autores ocidentais que cunharam, ou que os utilizam. Nos casos em que a especificidade da referência for julgada necessária, serão utilizados termos em escrita hieroglífica (doravante referida como Medu Neter).

${ }^{2}$ Em conversa com o Dr. Bayibayi acerca do que ele e o Dr. Bilolo entendem por esse termo utilizado por eles, ele me informou que "quando falo de meta-ontologia, refiro-me à concepção egipto-africana de Wunen e de Khepri (conceitos falados a seguir). Estes conceitos tratam do Devir do mundo, em oposição a sua permanência, isto é, "o que é". É um aspecto da totalidade, porque também existe "o que não é". Para o pensamento egipto-africano, o conceito de "Ser" é um momento do mundo, um momento que não conhecíamos, um momento do que agora vemos. $O$ mundo é o que foi, o que é e o que será. Wunen significa em CiBantu "alargar-se, estender, expandir", processo e progresso, mudança do ser, flutuação".
} 
particularidade da filosofia kemética). Se tomarmos como exemplo o papiro chamado pelo Dr. Asante (1990) de o Texto Filosófico Menfita, traduzido pelo egiptólogo americano James Breasted (1901), encontramos que a primeira etapa é caracterizada como um momento anterior ao tempo e seus registros, no qual se faziam presentes oito forças, as "II $44 \$ 3$ (termo traduzido de forma mais comum pelo modo como os gregos se referiram a ele mais tarde: "Octeto"), que representam os horizontes de possibilidades do real. Uma dessas forças, 000 . H $^{4}$ (comumente traduzida como "O oceano primordial") é dita anteceder o momento da origem do Demiurgo (cf. Texto Filosófico Menfita, 1. 50a).

Conforme o Dr. Karenga (2004, p. 192), o termo 000 \& era utilizado pelos povos keméticos para se referir à realidade que antecede a existência da realidade perceptível; em outras palavras, referia-se ao momento que para fins didáticos chamaremos aqui de pré-criação. Essas informações nos conduzem a uma interpretação diferente daquela opinião segundo a qual a concepção clássica africana considera o caos como uma entidade antecedente à ordem.

Considerando o Texto Filosófico Menfita, notamos que para a cultura clássica africana o momento que antecede a existência representa a potencialidade não estruturada, não ordenada e não realizada. Trata-se de uma qualidade de existência ainda não desenvolvida e ilimitada referente ao caráter indeterminado do universo externo. Em outras palavras, ela representa o lugar indefinido anterior ao "onde" definido do mundo. O Dr. Karenga (2004), citando outros egiptólogos, informa-nos que o caráter indeterminado

\footnotetext{
${ }^{3}$ Transliterado como hmnyw (GARDINER, 2007). Tratam-se de oito conceitos, apresentados como aspectos femininos e masculinos de 4 energias ditas presentes antes da existência da realidade, são eles (1) Nwn e seu aspecto feminino Naunet, representando as "águas primordiais"; (2) Hwh, as extensões sem limites da amorfidade primordial e seu aspecto feminino Hauhet; (3) Kwk, trevas, ou escuridão e seu aspecto feminino Kwket; e (4) Imen/Amen/Amon e seu aspecto feminino Amwnet, "o oculto, o mistério, o imperceptível", representando a intangibilidade e imperceptibilidade. Não encontramos no Texto Filosófico Menfita, corrompido em algumas partes, a menção a todas essas forças. Contudo, na linha 50 a do texto original a divindade Ptah é associada nominal e diretamente ao conceito de Nwn em seu aspecto de criadora de toda a realidade e criadora de todas as forças que subjazem o real. A menção completa é encontrada no Livro do Emergir à Luz do Dia (FAULKNER; GOELET; GUNTHER, 2015).

${ }^{4}$ Termo em medu neter transliterado como nwn (GARDINER, 2007).
} 
e ilimitado da pré-criação é transformado no processo de criação. E que a criação se

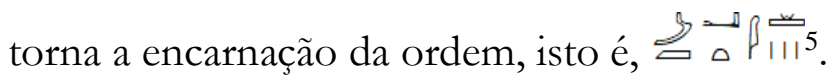

Essa etapa é seguida por outra, na qual uma realidade atômica, Ptah ${ }^{6}$, o Demiurgo, em seu aspecto de tomada de consciência de si mesmo enquanto existência é associado ao termo de Atom ${ }^{7}$, a partir da tomada de consciência de si mesmo e de se autoproclamar (cf. Texto Filosófico Menfita, 1. 3), isto é, verbalizar sua existência. Sendo, além disso, o princípio gerador de tudo que existe (ibid., 1l. 58-60):

Figura 1 - Excerto da Pedra de Shabaka
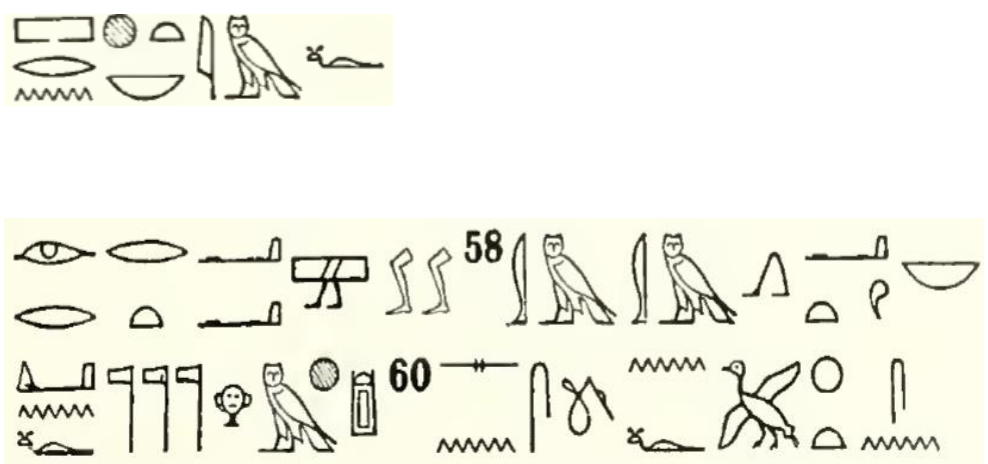

Todas as coisas [emergiram] a partir dele, quer seja a oferenda, a comida, ou (I. 59) a oferta divina, ou qualquer outra boa coisa [TEXTO CORROMPIDO] já que ele formou os deuses, fez as cidades, equipou os nomos, posicionou os deuses em seus santuários (I. 60), ele fez as oferendas florescerem, equipou seus santuários, fez a semelhança dos corpos para a satisfação de seus corações, então os deuses entraram em seus corpos, de toda a madeira, de toda a pedra preciosa, de todo o metal, e de todas as coisas (BREASTED, 1901, p. 461).

\footnotetext{
${ }^{5}$ Termo em medu neter transliterado como ma'at (BUDGE, 1920) e como M’'t (GARDINER, 2007).

${ }^{6}$ Pth (GARDINER, 2007) e transliterada como Ptah (BUDGE, 1920).

${ }^{7}$ Termo em medu neter transliterado como itm (GARDINER, 2007). Sabemos que no Ocidente, o conceito filosófico do Um (a realidade atômica) foi interpretado como um aspecto da realidade separado do restante, fator primordial para a fundação de um modo hierárquico de pensamento, o qual estabeleceu toda uma hierarquia social, religiosa, cultural e política, entendida como princípio de formação do Estado, como justificativa do mando e dos privilégios dirigidos a um gênero em detrimento de outro, uma cultura em detrimento de outra, um povo em detrimento de outro, uma religião em detrimento de outra, um modo de pensar em detrimento de outro. Contudo, tal não é o caso do Kemet, especialmente no período de florescimento do filósofo Ptah-Hotep, o Reino Antigo, cuja diversidade e intercambialidade conceitual são reflexo de uma interação mútua ente as várias culturas que compunham aquela civilização, com suas respectivas concepções de mundo, condensadas naquilo que o Dr. Karenga (2004) veio a chamar de Filosofia Maática.
} 
Essa porção atômica da realidade inaugura as qualidades de 8 , "Ser", e de " "Vir a Ser", (cf. Texto Filosófico Menfita, 1. 54), ora representado por um escaravelho (铚), ora representado pelo disco solar (O) — este também identificado com Ptah e com Rá, tomando aqui um sentido de "emergir", o qual será adotado por nós a partir de agora. Essa etapa é conhecida como Ocasião Primordial (cf. ASANTE, 1990, p. 20), termo recorrente nos textos keméticos. A etapa seguinte (que diz respeito à

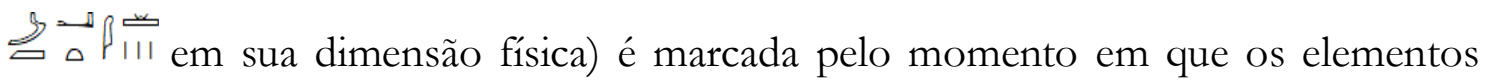

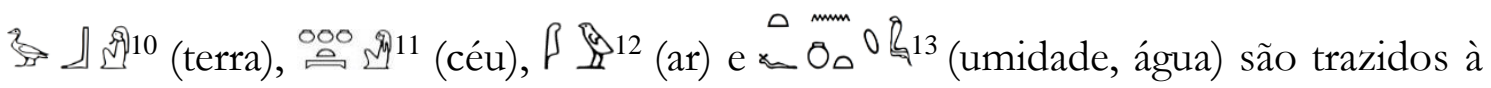
existência (cf. Texto Filosófico Menfita, 1. 55).

Com a existência desses elementos, que não surgiram de forma aleatória, mas a partir dos planos precisos de Ptah, o Demiurgo (cf. Texto Filosófico Menfita, 1l. 58-60), estão estabelecidas todas as condições para a etapa seguinte: a vida ${ }^{14}$, cujos suprimentos para sua continuidade e desenvolvimento são garantidos pela própria 7 . A etapa posterior é a da criação dos humanos, cujos primeiros ancestrais são Usir (ou Wsir, ou ainda Asar) ${ }^{15}$ (referido de forma mais comum pelo nome derivado do grego, Osíris) e Aset $^{16}$ (mais conhecida como Isis, como os gregos posteriormente se referiam).

Temos nesse relato da cultura clássica africana pelo menos duas asserções fundamentais: a primeira de que realidade alguma surge do nada. A categoria Nwn representa o aspecto não criado da realidade em sentido amplo, categoria cuja tradução "não criado" oferece grandes dificuldades ao nosso entendimento. Por esse motivo, seria prudente de nossa parte mantermos essa categoria como mais uma sem

\footnotetext{
${ }^{8}$ Transliterado pelas consoantes wnn (GARDINER, 2007).

${ }^{9}$ Transliterado como hpr (GARDINER, 2007). Utilizaremos a forma original dessa palavra ao falarmos dela. Por se tratar de um conceito-chave, e por ser a transliteração ainda atravessada pela intepretação ocidental, manteremos o original.

${ }^{10}$ Transliterado pelas consoantes gb (GARDINER, 2007).

${ }^{11}$ Transliterado pelas consoantes nwt (GARDINER, 2007).

${ }^{12}$ Transliterado pelos signos linguísticos šw (GARDINER, 2007).

${ }^{13}$ Transliterado pelas consoantes tfnwt (GARDINER, 2007).

${ }^{14} \mathrm{Em}$ medu neter (GARDINER, 2007).

${ }^{15}$ Transliteração da palavra em escrita kemética, convertida em egiptologia pelos signos consonantais wsir (GARDINER, 2007); noção diretamente relacionada com a Ancestralidade (cf. IMHOTEP, 2016).

${ }^{16}$ Em escrita kemética, convertida em egiptologia pelos signos consonantais ist (GARDINER, 2007). 
tradução. A segunda asserção que podemos extrair desse relato é a de que o que percebemos como a diversidade do real é o que por razões didáticas pode ser entendido como compartimentalizações do real. $\mathrm{O}$ verbo $\Rightarrow 17$, que pode ser traduzido como "nomear, proclamar" e que é utilizado para se referir ao exato momento em que Atom surge (ou toma consciência de si, se quisermos seguir a tradução do Dr. Breasted) tem como raiz o signo linguístico representado por uma foice, cuja principal função é cortar com precisão a vegetação no momento da colheita. Desse modo, o ato de nomear é estabelecer limites através da cisão, através do corte. Assim, o momento em que Atom "toma consciência de si", isto é, reconhece limites que o apresentam como algo distinto de Nwn é a maneira metafórica a partir da qual os povos keméticos apresentam a noção de identidade, de categorização — elemento fundamental daquilo que conhecemos hoje pelo conceito de ontologia. O reconhecimento da identidade corresponde à possibilidade da definição, da nomeação, isto é, o delineamento dos limites que diferenciam a realidade "antes" indiferenciada. Uma diferenciação que pode ser localizada em escala temporal e discernida em termos sequenciais de "surgimento" (sequência que pode ser percebida por nós à medida em que emerge aos nossos sentidos em suas diversas formas).

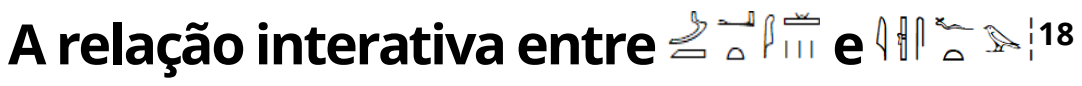

Para tratarmos da etapa seguinte, precisamos primeiro fazer uma digressão contextualizante, que nos põe diante da pedra angular da filosofia clássica africana, o paradigma de $\stackrel{2}{2}$ (KARENGA, 2004). Tal aspecto da realidade emerge no momento da criação como única força existente além de Ptah e que, assim como Ptah, pervade toda realidade. O nascimento de Usir, Aset, Neftys, Set e Heru demarca o surgimento da humanidade e a fundação de seus valores. O que nos põe diante de um aspecto social do paradigma kemético, que é a perspectiva ética dessa mitologia, contida no relato conhecido por egiptólogas e egiptólogos como o Drama de Osiris (ASANTE, 1990; DIOP, 1954; 2014).

\footnotetext{
17 Termo em escrita kemética, transliterado como m3̈t (GARDINER, 2007).

${ }^{18}$ Forma original do termo referente aos conceitos de "mal, caos, destruição", convertida em egiptologia pelos signos consonantais isft (GARDINER, 2007).
} 
Em linhas gerais, Wsir, reputado como o mais antigo ancestral da humanidade, compartilhava a realidade com seu irmão Set (divindade que representa a fúria) e suas irmãs, Aset (divindade da beleza, do amor, da vida e da fertilidade) e Neftys ${ }^{19}$ (divindade da maternidade e do cuidado). Invejoso da proeminência e importância do irmão Wsir, Set decide assassiná-lo brutalmente para tomar seu lugar. Aset gesta $\mathrm{Heru}^{20}$, filho de Wsir, que vinga a morte de seu pai, auxiliado por ela, transtornada com o ocorrido, e por Neftys, esposa de Set.

Em seguida os três se lançam em uma jornada de busca dos membros de Wsir, esquartejado e dividido em 14 partes pelo irmão (cf. IMHOTEP, 2020, p. 232) e espalhados por todo o Kemet. Após encontrar e reunir os membros de seu amado (com exceção do falo, representado ora pelo obelisco, ora pelo pilar djed), Aset restaura seu corpo e sua vida. Wsir é, portanto, o primeiro deus ressurreto. O drama de Wsir e sua ressurreição eram encenadas anualmente nos principais tempos do Kemet (cf. DIOP, 2014). O comentário realizado pelo Dr. Asante, em sua obra Filósofos Egípcios, acerca do caráter ético representado pelo relato do Drama de Wsir nos serve aqui como ferramenta didática:

Assim, quer fosse a partir de uma perspectiva individual, quer coletiva, o estabelecimento do mundo estava assentado sobre a busca constante pelo [...] estabelecimento da interconexão de todas as coisas, pela reconstrução do universo como ele era no início. Está implícita na ideia de início a antiga visão de que a Ocasião Primordial representava o modelo divino para os seres humanos. De fato, a Ocasião Primordial deve ser vista como um tipo de Constituição [...] dos antigos egípcios. Tudo que acontece nos tempos comuns pode estar conectado com aquilo que ocorrera na Ocasião Primordial [...], o reino das divindades. Isso é tanto uma abstração quanto uma representação simbólica dos deuses vivos e do relacionamento entre eles. Nossas experiências comuns se tornam de fato comuns porque são reflexos do que ocorrera na Ocasião Primordial. [Além das características específicas do processo de criação da realidade] as divindades interagiam umas com as outras e, em seus relacionamentos, estabeleceram padrões que reaparecem constantemente na realidade mundana. Mas, no fim, a conquista do bem sobre o mal acontece, embora possa levar um longo tempo e muitas circunstâncias de conflito [...] esse processo de reconectar o mundo, isto é, reconectar o universo como ele era foi o estabelecimento de Maat. A desconexão, a desorganização e o

\footnotetext{
${ }^{19}$ Palavra em escrita kemética, convertida em egiptologia pelos signos consonantais nbthyt (GARDINER, 2007).

${ }^{20}$ Transliteração da palavra em escrita kemética, convertida pelos signos consonantais ḥrw (GARDINER, 2007), referente à divindade representada pelo falcão, aquele que traz justiça. Para mais detalhes sobre essa divindade, seu papel e as virtudes às quais está vinculada, ver IMHOTEP, 2016.
} 
afastamento eram produtos de isfet, o mal, no mundo, e é apenas através de uma participação ativa da mente humana para readquirir sua centralidade e agência que os seres humanos retomam o momento da criação (ASANTE, 1990, p. 20).

As noções de harmonia social, representadas pela relação harmônica entre Wsir, Aset e Neftys, com as virtudes do amor e da fraternidade representadas por Aset, da empatia e do cuidado com o outro representadas por Neftys, da benevolência e da candura representadas por Wsir e da justiça representada por Heru, estabelecem virtudes cardeais, elementos fundamentais para a formação da pessoa kemética, desenvolvidas nos 1 \ 49 啚. Sobre esse aspecto, o Dr. Karenga (2004, p. 8), analisando os trabalhos do egiptólogo alemão Jan Assman acerca do pensamento ético do povo kemético e do filósofo ganense Kwame Gyekye sobre o pensamento filosófico Akan (destacando a unidade cultural africana), afirma haver na constituição do pensamento africano (kemético, em particular) o estabelecimento de uma sociedade comunitária focada nos relacionamentos, obrigações recíprocas e expectativas corretas relacionadas com o indivíduo. Para resumir a relação de forças em operação no sistema ético maático, nos serviremos de um trecho da análise do Dr. Karenga:

Por isso a necessidade de estar em harmonia com a ordem criada (natural, divina e social). O oposto de Maat: a má conduta, a prática de isfet (má conduta, mal, desordem, etc.). A prática de isfet conduz à destruição. Pois isfet é [...] aquilo que é perenemente derrotado na ordem do universo (Frankfort, 1961, p. 75) [...] a conduta humana mais bem sucedida, útil, própria (adequada) está cosmologicamente circunscrita (OBENGA, 1990, 158) [...] E a circunscrição expressa a si mesma na exigência e limites da ordem maática, a ordem da retidão no seu mais inclusivo significado. Assim, é a vida em maat que é verdadeiramente bem sucedida, e uma vida frutífera, [enquanto] a vida isfética convida a destruição e a falha (KARENGA, 2004, p. 8).

A existência do mal, 4 A $^{2}$, e do conflito gerado por ele, retratados na figura de Set e suas ações, a longa jornada de busca por justiça e restabelecimento da paz, retratadas pelo esforço coletivo incansável de Aset, Neftys e Heru, representam todo o drama da existência humana ao longo do Nilo, em sua luta coletiva contra a seca produzida pelo clima daquela região, que os obrigava a estocar alimento em grandes reservas do Estado (cf. IMHOTEP, 2016), contra as inundações violentas do caudaloso rio, cuja força e volume eram capazes de destruir habitações e ceifar vidas (JOCHANNAN, 1974), contra as pragas, as doenças e mesmo contra a própria 
natureza humana e seus vícios (cf. Sebayt de Ptah-Hotep; Sebayt de Kagemni; Sebayt de Amenemope).

Essa retratação do drama da jornada humana é apresentada também na representação do triunfo de Heru, Wsir e Aset sobre os atos de Set, que segundo Dr. Karenga (2004, p. 206) surge como paradigma de agressão, violação, caos, apropriação indébita, e apresentava aos seres humanos no quarto milênio antes da Era Comum a certeza do triunfo da perseverança, do esforço coletivo, da prática consistente e do ato criativo sobre a injustiça, o terror, o desagregamento e a destruição definitiva. Conforme Karenga (2004, p. 31), os Textos das Pirâmides (TP) estabelecem Lे como uma qualidade amada e recompensada com a vida, enquanto seu oposto, Af TP, o Dr. Karenga destaca 2

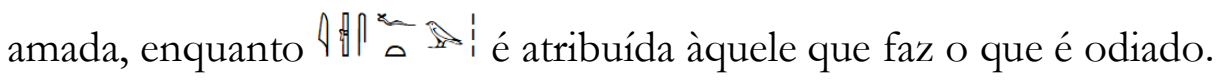

O Dr. Karenga (2004, p. 203) assevera haver um erro comum de entender o mal como advindo da natureza humana ao se tratar de questões como a origem, a natureza e o significado de 4 ftristo no mundo. Como destaca esse filósofo, nos Textos Funerários $(C T, 1130)$, quando o criador lista o que a tradição egiptológica classifica como os quatro bons atos, ele afirma ter feito todas as pessoas como iguais, porém não as

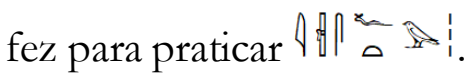

O Dr. Maulana (KARENGA, 2004, p. 204) acrescenta que a tradição ocidental interpreta a passagem acerca da existência e da presença do mal no mundo como sendo consequência da liberdade de esquecer a vontade de deus, porém esse filósofo alerta que o texto expressa ter sido a própria deliberação humana que que decidiu violar a vontade divina. Segundo a análise do Dr. Karenga, embora eles estejam corretos em afirmar que o mal existe desde o início, há uma inconsistência lógica em afirmar que o mal é consequência humana. Pois, ou (1) ele existia desde o início, ou (2) ele surgiu depois com os humanos.

Este filósofo afrocêntrico (KARENGA, 2004, p. 204) salienta que a primeira alternativa é verdadeira e que o mal é fruto do mau uso da faculdade de livre escolha.

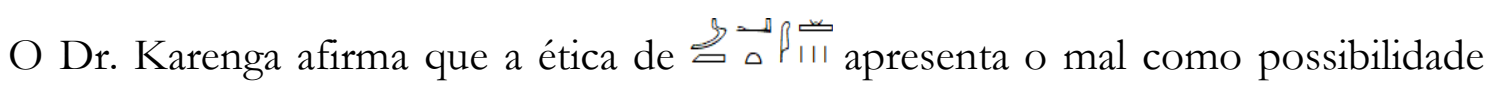
pessoal de desvio das máximas da lei moral. Ele afirma que a posição de Kant sobre 
a origem da natureza do mal é muito parecida com a concepção kemética, contudo, a ética e a ontologia maáticas não respondem à pergunta do mal como sendo ele uma parte constitutiva do ser humano. Não há nela o conceito de pecado original, ou mal por naturęa em relação aos humanos. Como ele nos informa (KARENGA, 2004, p. 204), a base para entender o mal como um princípio ontológico deve ser descoberto em

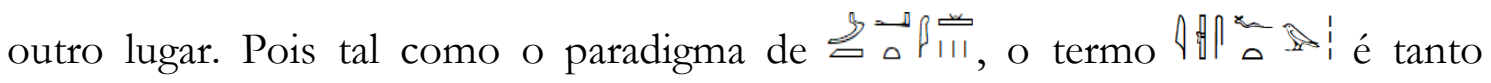
ontológico quanto ético. $4 \mathrm{Af}^{2}$ começo dos tempos, e posteriormente como confusão e crime, no princípio de Set, o mal e a desordem se sobrepõem e são intercambiáveis.

Ele ainda acrescenta (KARENGA, 2004, p. 204) que (1) em tempos mais tardios essas duas forças eram concebidas como existentes na pré-criação como tenem, o ilimitado primordial, que não é um mal moral, mas ontológico, sendo esse um pilar do entendimento sobre o mal. Em seu sentido literal, ele recebe as conotações de tornarse perdido e de desviar-se, enquanto em seu sentido figurativo conota o desviar-se do comportamento correto. Nesse sentido, 4 脚 2. estar fora das fronteiras de da criação fornece (KARENGA, 2004, p. 204). E (2) o conceito de desviar-se (também tenem), assim como as quatro outras qualidades, caracteriza o mundo da pré-criação e oferece um modelo de contraste com seus opostos no mundo criado e estabelecido por 2 (KARENGA, 2004, p. 204). O Dr. Karenga salienta que a tensão dinâmica entre a potencialidade e a atualidade contribui de alguma forma para o ato da criação.

\section{Considerações parciais}

Até o presente momento, conseguimos traçar um panorama inicial acerca da ontologia menfita. O Texto Filosófico Menfita nos informa ter a existência pelo menos dois aspectos. Em um deles, a realidade possui um caráter duplo de entidades subjacentes que interagem de forma contínua ( realidade se apresenta como um complexo de entidades, as 1114498 . 
Enquanto ordem ( 2 dimensões cósmica, natural e social, e também como garantidora da regularidade dos fenômenos e da existência (1) das leis da física, que possibilitam (na sua dimensão cósmica) uma relação harmônica entre os diferentes corpos celestes, como o sol, a lua e o nosso planeta, por exemplo, que garantem a existência da vida; (2) da regularidade de fenômenos, que (na sua dimensão natural) garante ao ser humano a possibilidade de apreensão de seus padrões e da consequente utilização dos mesmos para garantir sua sobrevivência; (3) da possibilidade (na sua dimensão humana) do reconhecimento, formulação e sistematização das leis sociais, que permitem a convivência duradoura, produtiva, não violenta e colaborativa entre esses seres.

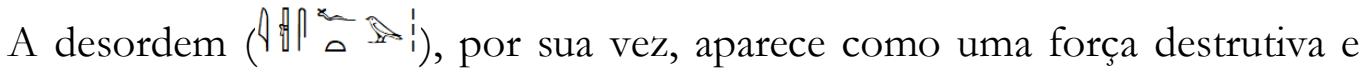
caótica que desafia duplamente a existência, expressão daquilo que é impuro, desordenado, mal, injusto e todas as coisas negativas ao ser, especialmente o ser enquanto vida (KARENGA, 2004, p. 184). Em outro de seus aspectos, a existência é relatada como a realidade complexa das "I! $44 \$$, sobre a qual não se aplicam noções como dimensão e temporalidade, por exemplo, configurada como o horizonte infinito de possibilidades.

Em termos ontológicos, os dados coletados até aqui já nos permitem dizer que para a tradição clássica africana, presente no Texto Filosófico Menfita, as noções que poderíamos chamar de caos e ordem surgem como realidades coexistentes do ser,

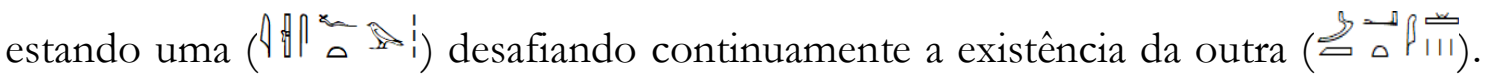
Outras questões emergem a partir dessa constatação. Dentre elas, poderíamos destacar algumas, como "Quais as principais características desses aspectos da existência?", ou "As implicações lógicas de tais definições produzem algum tipo de paradoxo?", ou ainda "Como se articulam as noções aparentemente incompatíveis de (1) uma existência cujos aspectos envolvem uma realidade criada, ordenada, localizada temporal e espacialmente, de interação sujeita a leis naturalmente estabelecidas, acessível à percepção e experimentação e de (2) uma realidade não criada, não realizada, atemporal, que transcende a temporalidade, a espacialidade, a percepção e que serve de horizonte de infinitas possibilidades de existência?

Embora as questões éticas levantadas aqui façam parte de nosso interesse, por uma questão de foco não iremos tratar das mesmas, sendo suficiente nessa ocasião 
destacarmos a característica sistemática típica da cultura clássica africana, que recebe o nome de "holismo" entre pesquisadoras e pesquisadores no assunto (ASANTE, 1990, p. 5; RIES et al., 1995, p. 332; KARENGA, 2004, p. 385).

A presente pesquisa nos forneceu um esboço da ontologia menfita e o conteúdo dos textos do qual o extraímos nos conduzem a uma concepção ontológica e cosmológica clássica africana diferente daquela assumida pela concepção comum, segundo a qual para os povos keméticos a ordem é precedida do caos na formação da realidade. O que podemos notar a partir do Texto Filosófico Menfita é que a realidade que conhecemos através dos órgãos dos sentidos possui um duplo aspecto existencial. Essa realidade é ordenada segundo princípios e leis transcendentes e coexiste com o aspecto da destruição, do caos, da desordem, do deixar de existir, aspecto sobre o qual também se impõem as mesmas leis transcendentes. Encontramos também no referido texto a informação segundo a qual a existência é composta por uma natureza complexa, a partir da qual existe uma realidade anterior às categorias de tempo e espaço. Nesse aspecto, tal realidade apresenta-se como eterna (e portanto não criada).

O aprofundamento da pesquisa nos conduz a outras questões: É possível extrairmos aspectos epistemológicos desse texto? Em caso de resposta positiva, é possível extrair dele questões/princípios de lógica? Estendendo os limites das questões, poderíamos formular algo como: Quais as implicações éticas de tal concepção? Já que as questões sobre ética se apresentam como um ramo da filosofia inseparável daquele ocupado com questões da física e da metafísica, como eram feitas essas relações? Quais problemas são elencados por essa tradição filosófica? Se existem forças transcendentes subjugando a própria constituição da realidade, elas também exercem esse mesmo poder sobre a capacidade humana de deliberar?

Essas são apenas algumas das questões estimuladas por nossa apresentação. Quer elas sejam respondidas, quer não, as novas perspectivas e caminhos argumentativos para que elas nos conduzem ampliam nossos horizontes e materializam os efeitos da promulgação da Lei no 10.639/03 no ambiente acadêmico.

\section{Referências}

ASANTE, M. K. The Afrocentric Idea. Philadelphia: Temple University Press, 1987. 
ASANTE, M. K. Kemet, Afrocentricity and Knowledge. Trenton: Africa World Press, 1990.

ASANTE, M. K. Uma Origem Africana da Filosofia: Mito ou Realidade? Capoeira Revista de Humanidades e Letras, v. 1, n. 1, 2014.

ASANTE, M. K. Afrocentricidade como Crítica do Paradigma Hegemônico Ocidental: Introdução a uma Ideia. Ensaios Filosóficos, v. 14, p. 9-18, 2016.

BAYIBAYI, J. M. Epistemología Africana y Concepciones teóricas: Reevaluar El Impacto De Los Presupuestos Sobre La Filosofía De Lo Real. 2017. 617f. Tese (Doutorado em Filosofia) Universitat Autònoma de Barcelona, Barcelona, 2017.

BILOLO, M. Meta-Ontologie Égyptienne du IIIe millénaire. Madwa Meta-Untu: Tum-Nunu ou Sha.Ntu. Munich-Kinshasa-Paris: PUA-AUP, 2008.

BREASTED, J. H. The First Philosophy: The Philosophy of a Memphite Priest. The Monist, v. XII, p. 458-479, 1901.

BUDGE, E. A. W. An Egypcian Hieroglyphic Dictionary: With an Index of English Words, King List, and Geographical List With Indexes, List of Hieroglyphic Characters, Coptic And Semitic Alphabets, Etc. London: John Murray, Trench \& Albemarle Street, 1920.

DIOP, C. A. A Unidade Cultural da África Negra: Esferas do Patriarcado e do Matriarcado na Antiguidade Clássica. Trad. Silvia Cunha Neto. Portugal: Pedago, 2014.

DIOP, C. A. Nations Nègres et Culture. Paris: Présence Africaine, 1954.

FAULKNER, R. O.; GOELET, O.; GUNTHER, D. The Egyptian Book of The Dead: The Book of Going Forth by Day: Being The Papyrus of Ani (Royal Scribe of The Divine Offerings). California: Chronicle Books, 2015.

GARDINER, A. H. Egyptian Grammar: Being an Introduction to the Study of Hieroglyphs. 3. ed. Cambridge: Friffith Institute Oxford, 2007.

IMHOTEP, A. Aaluja: Cyena-Ntu Religion \& Philosophy. v. II. Philadelphia: Madu-Ndela, 2020.

IMHOTEP, A. Nsw.t Biti (King) in Ancient Egyptian: A lesson in Paronimy an Leadership. Philadelphia: Madu-Ndela Press, 2016.

JOCHANNAN, J. B. The Black Man of The Nile: African Foundations of European Civilization and Thought. NY: Alkebulan Books, 1974.

KARENGA, M. Maat, the Moral Ideal in Ancient Egypt: an study in classical african ethics. New York: Routledge Press, 2004.

RIES, J. (Coord.) et al. Tratado de Antropología de lo Sagrado: Los origenes del homo religiosus. Trad. María Tabuya y Agustín López. Madrid: Ed. Trotta S. A., 1995. (Colección Paradigmas. Biblioteca de Ciencias de las religiones). 